\title{
Early Detection of Psychosis: Recent Updates from Clinical High-Risk Research
}

\author{
Ariel Schvarcz $\cdot$ Carrie E. Bearden
}

Published online: 18 January 2015

(C) Springer International Publishing AG 2015

\begin{abstract}
The debilitating nature of schizophrenia necessitates early detection of individuals at clinical high-risk (CHR) in order to facilitate early intervention. In particular, comparisons between those who develop fully psychotic features $(\mathrm{CHR}+)$ and those who do not (CHR-) offer the opportunity to reveal distinct risk factors for psychosis, as well as possible intervention target points. Recent studies have investigated baseline clinical, neurocognitive, neuroanatomic, neurohormonal, and psychophysiological predictors of outcome; premorbid social dysfunction, deficits in neurocognitive performance, neuroanatomic changes, and hypothalamicpituitary-adrenal (HPA) axis dysfunction have been implicated in psychosis emergence. However, several challenges within CHR research remain: heterogeneity in long-term diagnostic outcome, the variability of research tools and definitions utilized, and limited longitudinal follow-up. Future work in the field should focus on replication via extended longitudinal designs, aim to explore the trajectories and inter-relationships of hypothesized biomarkers, and continue to investigate interventions that seek to prevent psychosis emergence through symptom reduction.
\end{abstract}

This article is part of the Topical Collection on Psychosis

A. Schvarcz $\cdot$ C. E. Bearden

Department of Psychology, University of California, Los Angeles, 1285 Franz Hall, Box 951563, Los Angeles, CA 90095, USA

A. Schvarcz

e-mail: aschvar@ucla.edu

C. E. Bearden ( $\square)$

Department of Psychiatry \& Biobehavioral Sciences, Psychology, and Brain Research Institute, Semel Institute for Neuroscience and Human Behavior, University of California, Los Angeles, 300 Medical Plaza Room 2265, Los Angeles, CA 90095, USA e-mail: cbearden@mednet.ucla.edu
Keywords Clinical high-risk · Psychosis · Early detection · Clinical functioning $\cdot$ Neurocognition $\cdot$ Neuroimaging

\section{Introduction}

Schizophrenia is a debilitating disorder associated with poor long-term outcomes and large societal costs. Within the USA alone, the economic burden has been estimated around 60 billion dollars annually and is a direct consequence of reduced productivity, high direct medical costs (e.g., outpatient, inpatient, long-term care, and medication), and high non-health-care costs (e.g., living cost offsets) [1]. Recent work has highlighted the exacerbation of such costs by longer duration of untreated psychosis (DUP), which has been linked to more severe symptomatology, poorer global outcomes, decreased social functioning, and lower likelihood of remission $[2,3]$. The additional correlation between longer DUP and increased delays in accessing mental health services [3] emphasizes the need for early intervention and detection to minimize such morbidity.

Over the last two decades, a multitude of research has emerged focusing early detection efforts on the "clinical high-risk (CHR)" state (also known as "ultra high-risk" or putatively prodromal phase of illness), which refers to individuals identified as having prepsychotic clinical symptoms and functioning. In particular, the comparison between CHR individuals who ultimately develop fully psychotic features (CHR+, or converters) and those who do not (CHR- or nonconverters) suggests a potentially fruitful way of ascertaining distinct risk factors for the emergence of overt psychoticspectrum disorders, as well as possible intervention targets. With new literature on this population emerging daily, it seems 
prudent to draw attention to the most current work, and how it is shaping our understanding of psychosis prediction and the underlying mechanisms leading to illness onset. To that effect, this article aims to provide a comprehensive review of recent progress in the early detection and prediction of psychosis.

\section{Identifying the Clinical High-Risk State}

As referenced above, the CHR construct is broadly defined in terms of operationally defined thresholds of prepsychotic or subthreshold symptoms. Although the diagnostic tool varies slightly across sites (e.g., Structured Interview for Prodromal Syndromes [SIPS] [4], Comprehensive Assessment of At-Risk Mental State [CAARMS] [5], etc.), the criteria are typically defined as the presence of one or more of the following: attenuated positive symptoms (APS), brief intermittent psychotic symptoms (BIPS), and familial genetic risk or schizotypal personality disorder combined with prominent deterioration in functioning (GRD). Positive, negative, general, and disorganized symptoms are typically rated on a scale addressing typical/healthy ranges, prodromal ranges, and psychotic ranges. Other work has focused on basic symptoms, or cognitive abnormalities in domains such as language, perception, motivation, and/or thought processing that may reflect earlier stages of risk $[6 \bullet \bullet, 7,8 \bullet]$. The criteria for conversion to psychosis typically converge on the presence of at least one fully psychotic symptom occurring several times a week for at least 1 week to 1 month, depending on the interview. For recent, comprehensive reviews of CHR criteria and diagnostic instruments, readers are directed elsewhere $[6 \bullet \bullet, 7,8 \bullet]$.

Studies of the validity of the CHR state and research classification system have revealed some evidence of convergent, discriminant, and predictive power. Specifically, recent work from the North American Prodromal Longitudinal Study (NAPLS) consortium found that individuals who continue to meet CHR criteria over time as compared to symptomatic remitters (i.e., those no longer having symptoms in the prodromal range in any positive symptom domain, sustained for at least 6 months) were reported to have worse long-term functioning [9]. CHR status appeared distinct from symptoms meeting criteria for major depressive disorder; and those that met criteria for CHR status progression (i.e., an increase by at least one point in one positive symptom domain within a year) were more likely to convert to overt psychosis than those with stable CHR classification or those who remit.

\section{CHR Features and Factors Contributing to the Emergence of Psychosis}

\section{Clinical Symptoms and Functioning}

As compared to healthy controls (HC), CHR individuals were found to have a significantly greater impaired stress tolerance, despite similar rates of self-reported life events; in the CHR cohort, impaired stress tolerance was linked to poorer longterm global functioning and increases in depression, anxiety, conceptual disorganization, and total negative symptoms over a 4-year follow-up period, independent of the number of stressful life events [10]. Social and role functioning in CHR youth has also been separately predicted by negative symptoms and a composite neurocognitive factor within the multisite NAPLS cohort, with negative symptoms mediating the effects of neurocognition [11]. CHR individuals, those diagnosed with schizophrenia (SZ), and those with a first-degree family member with schizophrenia (genetic high risk, GHR) all perform similarly on tasks of emotion perception, and more poorly than $\mathrm{HC}$ [12]. However, patients with SZ performed more poorly than CHR individuals on tasks of emotion differentiation (i.e., distinguishing happy versus sad facial expressions), suggesting some emotion-based deficits may develop later in the course of illness. Yong et al. (2014) found that this decreased ability to recognize and label facial affect among CHRs, as well as deficits in theory of mind ability, were correlated with neurocognitive deficits in attention and working memory [13]. However, no control group was included in this study, limiting interpretability of the results.

Research on retrospective risk factors leading to the emergence and progression of psychosis has converged on premorbid social dysfunction. Poor adolescent social functioning has been shown to predict psychosis emergence over a 2.5-year follow-up, with high specificity and positive predictive power when combined with baseline-rated suspiciousness [14]. This relationship was observed irrespective of both early childhood social functioning and severity of most positive and negative symptoms at baseline. However, baseline disorganized communication, suspiciousness, social anhedonia, and reduced ideational richness mediated this relationship. Interestingly, observed decreases in role and global functioning over time did not predict conversion. Additionally, in this cohort poor adolescent social functioning was more likely to predict onset of schizophrenia as opposed to other psychotic disorders, suggesting some diagnostic specificity [15]. Further supporting this possibility, premorbid social functioning seems to differentiate future schizophrenia-spectrum disorders from other psychiatric conditions even when rated by school teachers of 10 to 13-year-old children at genetic high risk (GHR) for psychosis [16].

Other research using predictive models of observed longterm social and role deficits have confirmed the above 
findings. Both clinical and neuropsychological measures appear relevant; Carrion et al. found that baseline-evaluated social functioning, global disorganized symptomatology, and decreased processing speed predicted impaired social functioning at 3 to 5-year follow-up [17]. Similarly, poor role functioning, motor disturbances (e.g., clumsiness), and verbal memory deficits at baseline predicted later role outcome. However, only impaired social outcome significantly correlated with conversion to psychosis, while predictors of role outcome were independent of conversion. Therefore, while poor functioning in both domains persists among CHR patients, early social deficits again seem to confer specific vulnerability for psychosis. Gender differences may also be relevant to these findings, as Walder and colleagues (2013) found that baseline social functioning and overall positive symptom severity predicted conversion in male CHR patients only [18]. However, given that females were rated to have higher overall functioning at baseline in this study, and the fact that males demonstrated an association between greater deficits in childhood social adjustment and severity of later symptoms, these findings will need to be confirmed in an independent study.

In addition to the significance of early social dysfunction, the above work highlights the focus on baseline-rated features in the prediction of subsequent psychosis outcome. To investigate this further, one European study used latent class analysis to determine if certain baseline factors distinguished future CHR converters from non-converters [19]. While latent class membership failed to separate anything other than overall CHR participants and healthy controls, the baseline SIPS factor score was significantly higher in subsequent converters than non-converters. Specifically, higher total positive symptom scores (as well as higher cognitive disturbances scores on another semi-structured interview measure) indicated later conversion in an independent sample [20]. In a related investigation, baseline and 3- to 6-year follow-up ratings of global functioning (i.e., Global Assessment of Functioning (GAF); Quality of Life Scale) were split at the median, resulting in "good" and "poor" functioning groups [21]. Individuals were additionally characterized as "deteriorating" or "improving" based on functioning changes from baseline to a 3- to 6-year follow-up. Those meeting criteria for poor functioning at baseline and deteriorating function over time demonstrated the highest likelihood of converting to psychosis, with the deteriorating factor proving to be the most predictive (i.e., the "poor baseline functioning and improving function" group had lower conversion risk than the "high baseline functioning and deteriorating" group). This suggests that investigation of progressive changes in social and role functioning over time may be a better predictor of psychosis risk than is functioning at a single time point.

Substance use has also been investigated as a risk factor for conversion; in the Enhancing the Prospective Prediction of Psychosis (PREDICT) study, reduced use of alcohol (and not cannabis or tobacco) was a predictor of later psychosis [22]. However, this may be a proxy for increased social withdrawal as indicated by reduced social drinking, rather than a distinct predictor. A more comprehensive review of ten studies found that while CHR participants commonly reported use of cannabis, alcohol, and nicotine/tobacco, only two of the ten studies found a positive association between substance use and subsequent conversion to psychosis [23]. One found that nicotine and cannabis abuse were predictive (cannabis dependence was exclusionary) [24], and the other found that general substance abuse was associated with conversion when included in a multivariate prediction model [25]. However, as the authors highlight, most of the included studies analyzed only baseline or lifetime levels of substance use, rather than changes in usage over time throughout the study. Neuroimaging work has additionally proposed a schizophrenia-specific vulnerability to the effects of cannabis due to the correlation between structural brain changes and substance use observed in CHRs only $[23,26]$.

Additionally, some researchers have found that the presence of sexual abuse during childhood or adolescence, rather than broad presence of abuse or neglect, was associated with conversion [27]. Specifically, high sexual abuse scores on a self-report questionnaire led to a two- to fourfold increase in the rate of conversion as compared to those with low scores. This suggests that trauma-related stress may confer additional vulnerability for psychosis emergence, though additional work on abuse severity and frequency/duration is warranted.

\section{Neuropsychological Factors}

Neuropsychological studies have revealed differences in the overall cognitive functioning of CHR youth as compared to HCs. For example, in comparison to individuals who recently experienced their first psychotic episode (FE) and non-CHR help-seeking patients (HS), Magaud and colleagues (2014) found that CHRs do not show significant differences in overall IQ, nor on specific subscales, based on conventional statistical approaches (e.g., analysis of variance) [28]. However, analyses examining differences within subtests of an index revealed a higher proportion of diverse verbal comprehension profiles among CHR versus both FE and HS individuals. CHR individuals therefore appear to demonstrate specific patterns of subtle, early changes in their verbal cognition that may be best detected by investigating subscales rather than global index scores using classic analytic techniques.

Global intelligence has also been evaluated for its ability to predict psychosis emergence in conjunction with SIPS positive symptoms, with the combination producing a slightly more accurate prediction of conversion than SIPS positive symptoms alone [20]. In this study, both high severity of symptoms and low IQ were deemed the only factors to independently forecast psychosis from among a wide range of 
clinical and neurocognitive variables, over a 6-year follow-up period. Although both clinical and neurocognitive measures were assessed in conjunction with global functioning (GAF), only increased disorganization symptoms at baseline significantly correlated with poorer functioning at follow-up, suggesting a greater ability of clinical measures over neuropsychological ones to predict transition and long-term outcome. This has been affirmed through other work in which a best fit prediction model assessing several variables was created based on CHR APS criteria, basic symptoms of cognitive disturbances (COGDIS) and delayed processing speed [29]. Although the combination of clinical and neuropsychological features conferred the highest risk for conversion, individually, APS + COGDIS alone predicted conversion above and beyond the presence of processing speed deficits alone.

Studies examining neurocognitive predictors independent of positive or other symptoms have similarly been conducted with mixed findings. In a recent meta-analytic review, broad cognitive deficits (i.e., current and premorbid IQ, processing speed, visual and verbal memory, verbal and visuospatial working memory, attention, and fluency) were observed in CHR and GHR individuals as compared to healthy controls, with more severe cognitive deficits in all areas save sustained attention predicting conversion [30•]. However, modest effect sizes for baseline group differences between $\mathrm{CHR}+$ and $\mathrm{CHR}$ - again suggest a limited generalizability of baseline cognitive factors as stand-alone predictors of psychosis.

In contrast, another study examining pattern of changes in CHR neurocognitive ability over 1 year revealed that, among a large number of neuropsychological variables assessed, a significantly larger effect size for verbal memory deficits alone (e.g., failure of $\mathrm{CHR}+$ individuals to meet normative performance at the 1 year follow-up) was found for converters versus non-converters [31]. No differences were found in overall neuropsychological impairment or effect sizes for executive functioning scores at follow-up between $\mathrm{CHR}+$ and $\mathrm{CHR}$ - groups. However, overall CHR neurocognitive functioning was reduced at a 1-year follow-up relative to baseline, with executive function and verbal memory ability significantly below healthy control performance. No evidence was found for progressive changes in IQ in the CHR group, nor were group differences found between CHRs and $\mathrm{HC}$ in the domains of sustained attention and motor functioning. This work suggested that only progressive verbal memory impairments may be related to psychosis emergence, though the sample size and conversion rate here were notably small, especially given the short follow-up time period.

Using a slightly different approach in a Korean sample, CHR converters were compared to non-converters, full remitters, and $\mathrm{HC}$ to assess for baseline neurocognitive differences among the groups and prediction of symptom abatement over a 12- to 24-month follow-up [32]. At baseline, those whose prodromal symptoms subsequently remitted performed better on measures of verbal fluency and memory, immediate visual memory, and attention as compared to converters, and in fact performed equally to healthy controls in all cognitive domains. Over time, CHR remitters demonstrated improvement in semantic fluency while performance of non-remitting, nonconverting CHR individuals declined despite the absence of significant baseline differences, implying that investigation of cognitive trajectories over time may clarify probability of transition.

\section{Neuroimaging Factors}

Neuroimaging studies investigating high-risk cohorts have found abnormalities in the white matter organization in the brains of CHR individuals as compared to HCs using diffusion tensor imaging (DTI), particularly in brain regions known to undergo significant changes from adolescence to adulthood such as the superior longitudinal fasciculus [33]. However, to date no baseline differences between subsequent CHR converters and non-converters have been reported utilizing either DTI or volumetric techniques, though to date very few studies have reported on this comparison [34••].

Research using positron emission tomography (PET) to estimate dopamine synthesis capacity in the striatum found elevated dopamine synthesis capacity in the whole, associative, and sensorimotor (but not limbic) striatum, suggesting the presence of dopaminergic abnormalities that precede psychosis onset [35]. These intriguing findings have potential implications for early initiation of antipsychotic medications in these patients.

Findings related to the predictive utility of neuroanatomic findings have been inconsistent, in part due to methodological differences. Multivariate pattern classification has been used to classify converters and non-converters based on baseline group differences in gray matter volume in cerebellar, prefrontal, cingulate, and striatal structures, with classification algorithms attaining $80 \%$ accuracy in test cases [36]. When an independent sample of CHR participants were then classified into low, intermediate, and high-risk groups by the multivariate pattern analysis, low- versus high-risk group transition rates were 8 and $88 \%$, respectively, demonstrating fairly accurate conversion predictions from such neuroanatomic algorithms. However, while a recent review of the high-risk literature [34••] supports the notion of anatomic changes over time that distinguish $\mathrm{CHR}+$ from $\mathrm{CHR}$ - individuals, reports of baseline and follow-up group differences are inconsistent. For example, various studies have found that $\mathrm{CHR}+$ individuals demonstrate baseline volumetric abnormalities in several regions such as the interior frontal gyrus [37], prefrontal cortex [38], cerebellum [38], and cingulate cortex [38] as compared to non-converters, with particularly converging evidence for the insula [38, 39] and superior temporal gyrus $[37,38]$. Converters also have been reported to evidence 
greater volumetric reductions over time in the insular cortex [39], superior temporal gyrus [40], and inferior frontal gyrus [37] as compared to non-converters over a 1- to 4-year followup period.

Cortical thickness abnormalities have also been investigated, with no significant whole-brain or region of interest differences found between converters and non-converters despite overall decreased cortical thickness in the right parahippocampal gyrus observed in CHRs as compared to controls [41]. Importantly, findings from the NAPLS consortium in a sample of 135 controls and 274 CHR youth, 35 of whom converted, indicated no cortical thickness, or volumetric group differences at baseline, but significantly greater rates of change in cortical thickness in the superior frontal, middle frontal, and medial orbitofrontal regions within the right hemisphere in $\mathrm{CHR}+$ versus $\mathrm{CHR}-$ and HC groups [42] (see Fig. 1). CHR+ individuals also evidenced a greater expansion of the third ventricle over time as compared to CHR- and controls. These changes were not due to antipsychotic medication exposure as both medicated and non-medicated converters showed similar rates of gray matter loss. Additionally, converters demonstrated stronger correlations between rates of right hemisphere cortical thickness reduction and levels of pro-inflammatory markers measured in blood plasma, although this association was present among the entire sample. This work highlights the need for more research on the role of neuroinflammatory factors in psychosis onset and their temporal relationship to neurochemical and neuroanatomic changes.
Psychophysiological Factors

Various quantitative electroencephalogram (qEEG) parameters, such as resting EEG frequencies, have also been assessed for their utility in psychosis prediction [43]. These include alpha (awake, relaxed, closed-eye state), beta (active thinking state), theta (drowsy/meditative state; REM sleep), and delta (slow-wave sleep) activity. In the European Prediction of Psychosis Study (EPOS), variables of occipital-parietal alpha peak frequency (point of greatest power estimate within the alpha, frequency band), frontal delta, and frontal theta power were included in a final model and analyzed for prognostic power. Three classes of participants emerged (e.g., healthy controls, low psychosis-risk CHRs, and high psychosis-risk CHRs), with low- and high-risk CHRs demonstrating statistically significant different rates of conversions. Additionally, $\mathrm{CHR}+$ individuals were found to have higher frontal/central delta and theta and lower occipital-parietal alpha peak frequency, suggesting baseline resting EEG differences that can be used to predict later psychosis and potentially function as a point of individualized intervention. Resting state-EEG microstates, or transient patterns occurring during spontaneous mental operations, have also differentiated CHR patients from other symptomatic groups and HC [44]. Schizophrenic and CHR patients significantly differed in their temporal microstates as compared to controls, as well as from each other. In particular, microstate class A, one of the four typical microstates that may be active during phonological processing, seemed to most prominently predict transition to psychosis
Fig. 1 Statistical brain atlases from the NAPLS consortium neuroimaging study [42] reveal a significantly greater cortical thinning (warmer colors) over time in several, predominantly frontal brain regions (e.g., right superior frontal, middle frontal, and medial orbitofrontal regions) among CHR converters $(n=35)$ as compared to both non-converters $(n=239)$ and healthy controls $(n=135)$ (lower panel: FDR corrected, $p \leq .01$ )

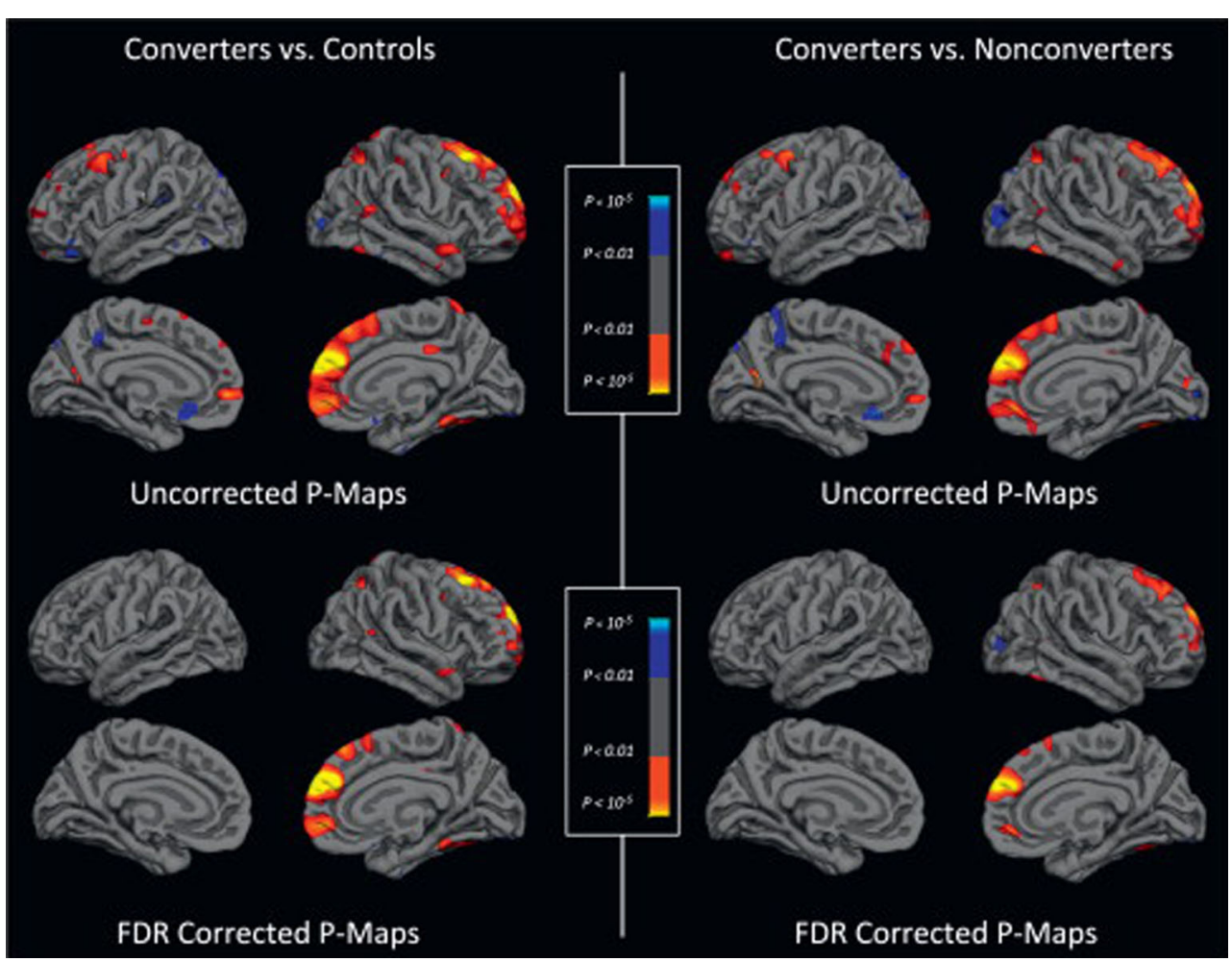


in light of its correlation with positive symptom severity, though it may also simply be a proxy for anxiety and impaired stress tolerance.

EEG-based event-related potential (ERP) work has additionally revealed a promising biomarker via auditory mismatch negativity (MMN), an ERP component resulting from hearing a discordant sound among repeated standard sounds. In a comparison of $\mathrm{CHR}, \mathrm{FE}$, and $\mathrm{HC}$ individuals, $\mathrm{HCs}$ had significantly higher MMN amplitudes compared to $\mathrm{FE}$ and CHR groups, while CHR and FE groups did not differ [45]. Within the CHR group, converters showed distinct profiles of lower MMN amplitudes at baseline compared to nonconverters; a finding that was not accounted for by antipsychotic medication. Further analysis suggested only one of two types of deviant MMN (double-deviant)-predicted psychosis when factoring in the time delay between ERP evaluation and conversion, highlighting more specific potential predictors for further evaluation.

\section{Neurohormonal Factors}

Previous research has implicated stress and underlying neurohormonal factors in the etiology of schizophrenia, such that indicators of hypothalamic-pituitary-adrenal (HPA) axis activity are elevated in individuals with psychotic-spectrum disorders and appear to be affected by both antipsychotic medications that reduce psychotic symptoms and recreational substances that exacerbate such symptoms [46, 47]. The association between elevated cortisol and dopamine activity in highrisk populations further suggests a role of neurohormonal factors in the emergence of psychosis [46]. Recently, two measures of HPA activity (salivary cortisol response to awakening and daytime salivary cortisol release) within a CHR cohort were examined [48]. CHR individuals, particularly those who were unmedicated, demonstrated a smaller cortisol awakening response compared to healthy controls. No group differences were observed within daytime cortisol levels nor were clinical symptoms significantly correlated with cortisol levels. However, the small sample size and confounds of medication plus psychosocial treatment throughout the study suggest notable limitations.

To better assess the predictive power of neurohormonal factors, the NAPLS consortium investigated salivary cortisol levels and found significant correlations to baseline symptoms across positive, negative, general, and disorganized domains, with particular significance for dysphoric mood and impaired stress tolerance [49]. Baseline cortisol levels among CHR+ patients were also found to be higher than that of CHR- or healthy control groups. Here too, effects were independent of antipsychotic or other medication use. Therefore, the role of HPA axis dysfunction as a potential risk biomarker warrants additional attention, particularly given recent reviews highlighting the role of stress and impaired immune functioning in the etiology of psychosis [50].

\section{Challenges Associated with CHR Research}

Despite the wealth of information we have accumulated from the CHR literature, several issues associated with the reliability and utility of the construct remain. One of the most prominent is the lack of specificity for determining later psychosis as opposed to other psychiatric disorders, broadly defined poor functioning, or brief psychotic symptoms that ultimately remit [51-55]. As some suggest, this may be partially due to limited long-term follow-up, research definitions of conversion that typically are based on psychotic-level symptomatology at a single time point, and the diversity of research tools and analytic strategies used among research sites [56, 57]. Variability in long-term outcome, specifically the high number of CHR individuals who do not convert to psychotic disorder, may also reflect access to effective intervention, sampling from heterogeneous help-seeking populations, and conversions occurring outside of study follow-up points [58]. Much of the CHR research to date has focused on relatively short follow-up periods, thereby potentially missing some cases of conversion ("false negatives") and confounding predictive algorithms. Some suggestions for increasing specificity have been proposed, such as including the COGDIS criterion into CHR criteria to increase the positive predictive power of conversion [59]. For example, the incorporation of basic symptoms at baseline has indeed been shown to increase the likelihood of predicting schizophrenia over affective psychosis [60], although this meta-analysis has been criticized for the use of limited, potentially underpowered studies [61]. Regardless, the inclusion of basic symptoms does not address the full spectrum of outlined concerns.

\section{Psychosis Risk Syndrome in DSM-V}

Many of the above arguments and challenges observed in CHR research put forth above became a part of the recent discussion and controversy regarding the inclusion of an attenuated psychosis syndrome into the Diagnostic and Statistical Manual of Mental Disorders, Fifth Edition (DSM-V) [62]. Although the full debate is beyond the scope of the current article, we highlight several themes and point the reader in the direction of more comprehensive reviews of the topic [7, 63]. As put forth by the DSM psychotic disorders task force, the defined attenuated psychotic symptoms (APS) syndrome significantly increases the likelihood of predicting future psychosis [64]. However, as highlighted above, limitations to the current evidence base exist: the overwhelming presence of 
comorbid diagnoses, the range of non-psychotic psychiatric outcomes, and the decreased diagnostic reliability among community clinical settings outside of the research or academic domains. Therefore, continued investigation of the syndrome and its connection to other related disorders like schizotypal personality disorder is necessary before inclusion into the DSM as a formal disorder.

\section{Summary and Conclusions}

Recent research has continued to clarify the CHR state and long-term outcomes, finding that negative symptoms in CHR individuals predict deficits in functioning at baseline and follow-up, and that decreased functioning correlates with neurocognitive factors across all time points [11]. In particular, premorbid social dysfunction appears to have some diagnostic specificity for predicting emergence of schizophrenia over other psychiatric outcomes, including other psychotic disorders. Additionally, the combination of clinical and neuropsychological variables such as IQ, verbal memory, or processing speed increases predictive power [20, 29]. Baseline differences in neuroanatomic structures have also been reported in CHR versus $\mathrm{HC}$ groups, with structural differences in the superior temporal gyrus and insula appearing in multiple studies. Progressive gray matter changes within several anatomic regions may be particularly relevant as predictors of psychosis outcome, although the implicated regions vary across studies. HPA axis dysfunction is also hypothesized to be relevant to psychosis risk; this possibility is supported by the finding of elevated baseline cortisol levels among CHR + individuals. Lastly, most of the recent work conducted has focused on baseline predictors of psychosis, though it has also been suggested that the field should shift to assessing overall deterioration throughout study duration. Table 1 provides a summary of the clinical and neurocognitive prediction findings, while Table 2 summarizes neuroimaging, psychophysiological, and neurohormonal predictors of transition to psychosis.

Despite this progress, findings across studies do not yet fully converge on common factors, highlighting the complex nature of schizophrenia and its etiology [65•]. Therefore, there are still many areas requiring clarification within the psychosis risk prediction literature. As with all budding research, many findings need to be replicated using larger sample sizes and

Table 1 Recent clinical and neurocognitive predictors of transition to psychosis (individual studies)

\begin{tabular}{|c|c|c|c|c|c|c|}
\hline Source & HR group & Sample size ${ }^{a}$ & $\begin{array}{l}\text { CHR diagnostic } \\
\text { tools }\end{array}$ & CR $(\%)$ & $\begin{array}{l}\text { Follow-up } \\
\text { (years) }\end{array}$ & Predictors \\
\hline Tarbox et al., 2013 [14] & CHR & 270 & SIPS & 28.9 & 2.5 & (1) Impaired early adolescent social functioning \\
\hline Tarbox et al., 2014 [15] & $\mathrm{CHR}+$ & 54 & SIPS & $\mathrm{N} / \mathrm{A}^{\mathrm{b}}$ & 2.5 & (1) Impaired late adolescent social functioning \\
\hline Tsuji et al., 2013 [16] & GHR & 244 & Psychiatric records $^{\mathrm{c}}$ & 13.5 & 20 & $\begin{array}{l}\text { (1) Teacher-rated impaired childhood social } \\
\text { functioning }\end{array}$ \\
\hline Carrión et al., 2013 [17] & CHR & 92 & SIPS & 16.3 & 5.0 & (1) Impaired social long-term functioning \\
\hline Walder et al., 2013 [18] & CHR & 276 & SIPS & 25.4 & 2.5 & $\begin{array}{l}\text { (1-2) BL social functioning and SIPS positive } \\
\text { symptoms among male CHRs only }\end{array}$ \\
\hline Velthorst et al., 2013 [19] & CHR & 147 & SIPS; PANSS & 19.0 & 2.0 & (1) Higher BL SIPS factor score \\
\hline Ziermans et al., 2014 [20] & CHR & 43 & SIPS; BSABS & 23.3 & 6.0 & $\begin{array}{l}\text { (1) BL SIPS positive symptom severity } \\
\text { (2) BL BSABS cognitive disturbances severity } \\
\text { (3) BL impaired full-scale IQ }\end{array}$ \\
\hline Velthorst et al., 2013 [21] & $\mathrm{CHR}$ & 157 & CAARMS; SANS & 21.0 & 6.0 & (1) Low + deteriorating functioning \\
\hline Buchy et al., 2014 [22] & CHR & 170 & SIPS & 17.1 & 4.0 & (1) Reduced BL alcohol consumption \\
\hline Thompson et al., 2013 [27] & CHR & 233 & $\begin{array}{l}\text { CAARMS; BPRS; } \\
\text { CASH }\end{array}$ & 23.6 & $7.0^{\mathrm{d}}$ & (1) Self-reported childhood sexual abuse \\
\hline Michel et al., 2014 [29] & CHR & 97 & SIPS; SPI & 45.4 & 2.0 & $\begin{array}{l}\text { (1) APS + COGDIS at-risk criteria } \\
\text { (2) Processing speed }\end{array}$ \\
\hline Woodberry et al., 2013 [31] & CHR & 53 & SIPS & 18.9 & 1.0 & (1) Large effect size for verbal memory deficits \\
\hline
\end{tabular}

$H R$ high-risk, $C R$ conversion rate, SIPS Structured Interview for Prodromal Syndromes, $N / A$ not applicable, $B L$ baseline, PANSS Positive and Negative Syndrome Scale, BSABS Bonn Scale for the Assessment of Basic Symptoms, CAARMS Comprehensive Assessment of At-Risk Mental State, SANS Scale for the Assessment of Negative Symptoms, BPRS Brief Psychiatric Rating Scale, CASH Comprehensive Assessment of Symptoms and History, SPI Schizophrenia Proneness Instrument

${ }^{\text {a }}$ Of HR group only

${ }^{\mathrm{b}}$ All participants in study had converted

${ }^{\mathrm{c}}$ GHR status established through psychiatric hospital diagnosis of schizophrenia

${ }^{\mathrm{d}}$ Average follow-up time 
Table 2 Recent neuroimaging, psychophysiological, and neurohormonal predictors of transition to psychosis (individual studies)

\begin{tabular}{|c|c|c|c|c|c|c|}
\hline Source & $\begin{array}{l}\text { HR } \\
\text { Group }\end{array}$ & $\begin{array}{l}\text { Sample } \\
\text { Size }^{\mathrm{a}}\end{array}$ & $\begin{array}{l}\text { CHR Diagnostic } \\
\text { Tools }\end{array}$ & $\begin{array}{l}\text { CR } \\
(\%)\end{array}$ & $\begin{array}{l}\text { Follow-up } \\
\text { (yrs) }\end{array}$ & Predictors \\
\hline $\begin{array}{l}\text { Van Tricht et al., } \\
2014[43]\end{array}$ & CHR & 113 & SIPS; SPI & 19.5 & 1.5 & $\begin{array}{l}\text { (1) Occipital-parietal APF } \\
\text { (2) frontal delta power } \\
\text { (3) frontal theta power }\end{array}$ \\
\hline $\begin{array}{l}\text { Andreou et al., } \\
2014[44]\end{array}$ & $\mathrm{CHR}^{\mathrm{b}}$ & 18 & $\begin{array}{l}\text { SIPS; SPI; } \\
\text { PANSS }\end{array}$ & NR & NR & (1) Temporal microstate A \\
\hline $\begin{array}{l}\text { Perez et al., } 2014 \\
{[45]}\end{array}$ & $\mathrm{CHR}^{\mathrm{b}}$ & 38 & SIPS; PANSS & 39.5 & 2.5 & $\begin{array}{l}\text { (1) Smaller MMN amplitudes (2) greater MMN deficits (3) } \\
\text { Double-deviant } \mathrm{MMN}^{\mathrm{c}}\end{array}$ \\
\hline $\begin{array}{l}\text { Koutsouleris et al., } \\
2014[36]\end{array}$ & CHR & 73 & $\begin{array}{l}\text { BSIP; BPRS, } \\
\text { SANS, PANSS }\end{array}$ & 45.2 & 4.0 & $\begin{array}{l}\text { (1) Reduced GM in bilateral prefrontal and lateral subcortical } \\
\text { structures (basal ganglia, cerebellar lobules, vermal lobules) } \\
\text { (2) Increased GM in lateral perisylvian/ temporal and } \\
\text { subcortical structures (pallidum, verbal lobules, cerebellar } \\
\text { lobules) }\end{array}$ \\
\hline $\begin{array}{l}\text { Tognin et al., } 2014 \\
\text { [41] }\end{array}$ & CHR & 167 & $\begin{array}{l}\text { CAARMS; BSIP; } \\
\text { BSABS }\end{array}$ & 29.9 & 2.0 & $\begin{array}{l}\text {--None reported (trend for cortical thinning in inferior frontal } \\
\text { gyrus) }\end{array}$ \\
\hline $\begin{array}{l}\text { Cannon et al., } \\
2015[42]\end{array}$ & CHR & 274 & SIPS & 12.8 & 12 & $\begin{array}{l}\text { (1) Steeper rates of cortical thinning in superior frontal, middle } \\
\text { frontal, and medial orbitofrontal gyri } \\
\text { (2) Greater third ventricle expansion } \\
\text { (3) Greater correlation between prefrontal cortical thinning and } \\
\text { high levels of proinflammatory markers }\end{array}$ \\
\hline $\begin{array}{l}\text { Walker et al., } 2013 \\
\text { [49] }\end{array}$ & CHR & $256^{\mathrm{d}}$ & SIPS & $23.5^{\mathrm{d}}$ & 24 & (1) Higher BL cortisol levels \\
\hline
\end{tabular}

Color-coding: blue = psychophysiological studies, pink = neuroimaging studies, yellow $=$ neurohormonal studies

$H R$ high-risk, $C R$ conversion rate, SIPS Structured Interview for Prodromal Syndromes, SPI Schizophrenia Proneness Instrument, PANSS Positive and Negative Syndrome Scale, NR not reported, BSIP Basel Screening Instrument for Psychosis, BPRS Brief Psychiatric Rating Scale, SANS Scale for the Assessment of Negative Symptoms, GM gray matter, CAARMS Comprehensive Assessment of At-Risk Mental State, BSABS Bonn Scale for the Assessment of Basic Symptoms, BL baseline

${ }^{\text {a }}$ Of HR group only

${ }^{\mathrm{b}}$ As compared to $\mathrm{FE} / \mathrm{SZ}$ and $\mathrm{HC}$

${ }^{\mathrm{c}}$ Predicts time to conversion

${ }^{\mathrm{d}}$ Prediction analyses were conducted on subset of 136 individuals

extended longitudinal designs to confirm their validity and reliability; multisite studies such as the NAPLS consortium (e.g., [23]) may prove to be particularly useful here. It will also be imperative to pin down the timing and trajectories of suggested biomarkers in order to facilitate intervention. Although recent publications have highlighted promising interventions that seek to prevent psychosis emergence via symptom reduction, such as medications including Omega-3 fatty acids [66-68] and glycine [69], psychosocial therapies [70-74], cognitive remediation training [75], and combined treatment approaches [76•, 77], this field is still in its infancy.

Among other factors, potential regional/cultural variability in help-seeking behavior and health-care programs [78, 79] has not yet been sufficiently addressed. Additionally, there continues to be a paucity of current research on the ethnic and cultural differences in CHR classification and outcomes, as well as whether distinct conversion predictors exist within ethnic groups as some have suggested [80]. From a clinical standpoint, delays in obtaining access to care also present a substantial obstacle to receiving accurate early diagnosis and treatment. Future work must also continue focusing on improving functioning and symptom reduction via more comprehensive and multimodal wrap-around services [1, 66, 81], and including empirically supported treatments for schizophrenia such as psychosocial therapy and mindfulness interventions [82-85]. Given observed progressive declines in global cognitive function in patient with schizophrenia over time [86], increased participation in cognitive remediation training programs [87-89] and/or cognitive control programs [90] may be additionally useful. Lastly, researchers and clinicians alike should aim to reduce the gap between their respective fields in order to facilitate widespread utility of CHR classification and intervention. This likely begins with addressing classification discrepancies and refining clinical/ research tools as needed; specifically, whether it is more efficacious to define psychosis from a dichotomous or continuous perspective. The adoption of low-cost screening methods may also prove fruitful here [91, 92].

In conclusion, many important findings in CHR research have emerged over the past year, particularly in the domain of clinical functioning. This field continues to progress in its attempts to clarify both clinical and biological markers of 
psychosis risk and has begun to offer important insight into interventions for reducing the likelihood of psychosis emergence. Although more work is necessary to elucidate and expand the current literature, we have started gaining traction on utilizing research findings to reach a point of meaningful intervention and prevention of psychosis.

\section{Compliance with Ethics Guidelines}

Conflict of Interest Carrie Bearden and Ariel Schvarcz have no conflicts of interest.

Human and Animal Rights and Informed Consent This article does not contain any studies with human or animal subjects performed by any of the authors.

\section{References}

Papers of particular interest, published recently, have been highlighted as:

- Of importance

•- Of major importance

1. Lieberman JA, Dixon LB, Goldman HH. Early detection and intervention in schizophrenia: a new therapeutic model. JAMA. 2013;310(7):689-90. doi:10.1001/jama.2013.8804.

2. Penttilä M, Jääskeläinen E, Hirvonen N, Isohanni M, Miettunen J. Duration of untreated psychosis as predictor of long-term outcome in schizophrenia: systematic review and meta-analysis. Br J Psychiatry. 2014;205(2):88-94. doi:10.1192/bjp.bp.113.127753.

3. Birchwood M, Connor C, Lester H, Patterson P, Freemantle N, Marshall M, et al. Reducing duration of untreated psychosis: care pathways to early intervention in psychosis services. Br J Psychiatr. 2013;203(1):58-64. doi:10.1192/bjp.bp.112.125500.

4. Miller TJ, McGlashan TH, Rosen JL, Cadenhead K, Ventura J, McFarlane W, et al. Prodromal assessment with the structured interview for prodromal syndromes and the scale of prodromal symptoms: predictive validity, interrater reliability, and training to reliability. Schizophr Bull. 2003;29(4):703-15.

5. Yung AR, Yuen HP, McGorry PD, Phillips LJ, Kelly D, Dell'Olio $\mathrm{M}$, et al. Mapping the onset of psychosis: the Comprehensive Assessment of At-Risk Mental States. Aust N Z J Psychiatr. 2005;39(11-12):964-71. doi:10.1111/j.1440-1614.2005.01714.x.

6.• Fusar-Poli P, Borgwardt S, Bechdolf A, Addington J, RiecherRossler A, Schultze-Lutter F, et al. The psychosis high-risk state: a comprehensive state-of-the-art review. JAMA Psychiatr. 2013;70(1):107-20. doi:10.1001/jamapsychiatry.2013.269. Thorough synthesis of CHR literature suggests vulnerability markers exist in all reviewed domains but with little certainty on their diagnostic specificity.

7. O'Connor K. Research in young people at ultra-high risk for psychosis: a review of the current evidence. Ir J Psychol Med. 2013;30(01):77-89. doi:10.1017/ipm.2012.9.

8. Gur RE. Early detection of psychosis: challenges and opportunities. Curr Behav Neurosci Rep. 2014;1(2):117-24. doi:10.1007/s40473014-0012-3. Recent review of clinical-high risk literature with focus on methods of neural assessment (e.g., neurotransmitters, neuroimaging, etc.).

9. Woods SW, Walsh BC, Addington J, Cadenhead KS, Cannon TD, Cornblatt BA, et al. Current status specifiers for patients at clinical high risk for psychosis. Schizophr Res. 2014;158(1-3):69-75. doi: 10.1016/j.schres.2014.06.022.

10. DeVylder JE, Ben-David S, Schobel SA, Kimhy D, Malaspina D, Corcoran CM. Temporal association of stress sensitivity and symptoms in individuals at clinical high risk for psychosis. Psychol Med. 2013;43(02):259-68. doi:10.1017/S0033291712001262.

11. Meyer EC, Carrión RE, Cornblatt BA, Addington J, Cadenhead $\mathrm{KS}$, Cannon TD et al. The relationship of neurocognition and negative symptoms to social and role functioning over time in individuals at clinical high risk in the first phase of the North American Prodrome Longitudinal Study. Schizophr Bull. 2014;sbt235. doi: $10.1093 / \mathrm{schbul} / \mathrm{sbt} 235$.

12. Kohler CG, Richard JA, Brensinger CM, Borgmann-Winter KE, Conroy CG, Moberg PJ, et al. Facial emotion perception differs in young persons at genetic and clinical high-risk for psychosis. Psychiatr Res. 2014;216(2):206-12. doi:10.1016/j.psychres.2014. 01.023.

13. Yong E, Barbato M, Penn DL, Keefe RSE, Woods SW, Perkins DO, et al. Exploratory analysis of social cognition and neurocognition in individuals at clinical high risk for psychosis. Psychiatry Res. 2014;218(1-2):39-43. doi:10.1016/j.psychres.2014.04.003.

14. Tarbox SI, Addington J, Cadenhead KS, Cannon TD, Cornblatt BA, Perkins DO et al. Premorbid functional development and conversion to psychosis in clinical high-risk youths. Dev Psychopathol. 2013;25(4pt1):1171-1186. doi:10.1017/S0954579413000448.

15. Tarbox SI, Addington J, Cadenhead KS, Cannon TD, Cornblatt BA, Perkins DO, et al. Functional development in clinical high risk youth: prediction of schizophrenia versus other psychotic disorders. Psychiatr Res. 2014;215(1):52-60. doi:10.1016/j.psychres.2013. 10.006.

16. Tsuji T, Kline E, Sorensen HJ, Mortensen EL, Michelsen NM, Ekstrom M, et al. Premorbid teacher-rated social functioning predicts adult schizophrenia-spectrum disorder: a high-risk prospective investigation. Schizophr Res. 2013;151(1-3):270-3. doi:10.1016/j. schres.2013.10.022

17. Carrión RE, McLaughlin D, Goldberg TE, et al. Prediction of functional outcome in individuals at clinical high risk for psychosis. JAMA Psychiatr. 2013;70(11):1133-42. doi:10.1001/ jamapsychiatry.2013.1909.

18. Walder DJ, Holtzman CW, Addington J, Cadenhead K, Tsuang M, Cornblatt B, et al. Sexual dimorphisms and prediction of conversion in the NAPLS psychosis prodrome. Schizophr Res. 2013;144:4350. doi:10.1016/j.schres.2012.11.039.

19. Velthorst E, Derks EM, Schothorst P, Becker H, Durston S, Ziermans T, et al. Quantitative and qualitative symptomatic differences in individuals at ultra-high risk for psychosis and healthy controls. Psychiatr Res. 2013;210(2):432-7. doi:10.1016/j. psychres.2013.07.018.

20. Ziermans T, de Wit S, Schothorst P, Sprong M, van Engeland H, Kahn R, et al. Neurocognitive and clinical predictors of long-term outcome in adolescents at ultra-high risk for psychosis: a 6-year follow-up. PLoS ONE. 2014;9(4):e93994. doi:10.1371/journal. pone.0093994.

21. Velthorst E, Nelson B, Wiltink S, de Haan L, Wood SJ, Lin A, et al. Transition to first episode psychosis in ultra high risk populations: does baseline functioning hold the key? Schizophr Res. 2013;143(1):132-7. doi:10.1016/j.schres.2012.10.025.

22. Buchy L, Perkins D, Woods SW, Liu L, Addington J. Impact of substance use on conversion to psychosis in youth at clinical high risk of psychosis. Schizophr Res. 2014;156(2-3):277-80. doi:10. 1016/j.schres.2014.04.021.

23. Addington J, Case N, Saleem MM, Auther AM, Cornblatt BA, Cadenhead KS. Substance use in clinical high risk for psychosis: a review of the literature. Early Interv Psychiatr. 2014;8(2):104-12. doi:10.1111/eip.12100. 
24. Kristensen K, Cadenhead KS. Cannabis abuse and risk for psychosis in a prodromal sample. Psychiatry Res. 2007;151(1-2):151-4. doi:10.1016/j.psychres.2006.10.001.

25. Cannon TD, Cadenhead K, Cornblatt B, et al. Prediction of psychosis in youth at high clinical risk: a multisite longitudinal study in North America. Arch Gen Psychiatry. 2008;65(1):28-37. doi:10. 1001/archgenpsychiatry.2007.3.

26. Rapp C, Walter A, Studerus E, Bugra H, Tamagni C, Röthlisberger $\mathrm{M}$ et al. Cannabis use and brain structural alterations of the cingulate cortex in early psychosis. Psychiatr Res: Neuroimaging. 2013;214(2):102-108. doi:10.1016/j.pscychresns.2013.06.006.

27. Thompson AD, Nelson B, Yuen HP, Lin A, Amminger GP, McGorry PD et al. Sexual trauma increases the risk of developing psychosis in an ultra high-risk "prodromal" population. Schizophr Bull. 2013;sbt032. doi:10.1093/schbul/sbt032.

28. Magaud E, Morvan Y, Rampazzo A, Alexandre C, Willard D, Gaillard R et al. Subjects at ultra high risk for psychosis have "heterogeneous" intellectual functioning profile: a multiple-case study. Schizophr Res. 2014;152(2-3), 415-420. doi:10.1016/j. schres.2013.11.002.

29. Michel C, Ruhrmann S, Schimmelmann BG, Klosterkötter J, Schultze-Lutter F. A stratified model for psychosis prediction in clinical practice. Schizophr Bull. 2014;sbu025. doi:10.1093/ schbul/sbu025.

30. Bora E, Lin A, Wood SJ, Yung AR, McGorry PD, Pantelis C. Cognitive deficits in youth with familial and clinical high risk to psychosis: a systematic review and meta-analysis. Acta Psychiatr Scand. 2014;130(1):1-15. doi:10.1111/acps.12261. Review of neurocognitive studies reveals presence of widespread premorbid deficits that confer vulnerability for later psychosis onset.

31. Woodberry KA, McFarlane WR, Giuliano AJ, Verdi MB, Cook WL, Faraone SV, et al. Change in neuropsychological functioning over one year in youth at clinical high risk for psychosis. Schizophr Res. 2013;146(1-3):87-94. doi:10.1016/j.schres.2013.01.017.

32. Lee TY, Shin YS, Shin NY, Kim SN, Jang JH, Kang D-H, et al. Neurocognitive function as a possible marker for remission from clinical high risk for psychosis. Schizophr Res. 2014;153(1-3):4853. doi:10.1016/j.schres.2014.01.018.

33. Hohenberg CC, von, Pasternak O, Kubicki M, Ballinger T, Vu M$\mathrm{A}$, Swisher $\mathrm{T}$ et al. White matter microstructure in individuals at clinical high risk of psychosis: a whole-brain diffusion tensor imaging study. Schizophr. Bull. 2013;sbt079. doi:10.1093/schbul/ sbt079.

34.• Bois C, Whalley HC, McIntosh AM, Lawrie SM. Structural magnetic resonance imaging markers of susceptibility and transition to schizophrenia: a review of familial and clinical high risk population studies. J Psychopharmacol. 2014. doi:10.1177/0269881114541015. Review of neuroimaging studies suggests structural abnormalities precede psychosis onset and provide a useful prediction framework.

35. Egerton A, Chaddock CA, Winton-Brown TT, Bloomfield MAP, Bhattacharyya S, Allen P et al. Presynaptic striatal dopamine dysfunction in people at ultra-high risk for psychosis: findings in a second cohort. Biol Psychiatr. 2013;74(2):106-112. doi:10.1016/j. biopsych.2012.11.017.

36. Koutsouleris N, Riecher-Rössler A, Meisenzahl EM, Smieskova R, Studerus E, Kambeitz-Ilankovic L et al. Detecting the psychosis prodrome across high-risk populations using neuroanatomical biomarkers. Schizophr Bull. 2014;sbu078. doi:10.1093/schbul/ sbu078.

37. Fusar-Poli P, Borgwardt S, Crescini A, Deste G, Kempton MJ, Lawrie $S$ et al. Neuroanatomy of vulnerability to psychosis: a voxel-based meta-analysis. Neurosci Biobehav Rev. 2011;35(5), 1175-1185. doi:10.1016/j.neubiorev.2010.12.005.

38. Smieskova R, Fusar-Poli P, Allen P, Bendfeldt K, Stieglitz RD, Drewe $\mathrm{J}$ et al. Neuroimaging predictors of transition to psychosis - a systematic review and meta-analysis. Neurosci Biobehav
Rev. 2010;34(8):1207-1222. doi:10.1016/j.neubiorev.2010.01. 016.

39. Takahashi T, Wood SJ, Yung AR, Phillips LJ, Soulsby B, McGorry $\mathrm{PD}$ et al. Insular cortex gray matter changes in individuals at ultrahigh-risk of developing psychosis. Schizophr Res. 2009;111(1-3): 94-102. doi:10.1016/j.schres.2009.03.024.

40. Takahashi T, Wood SJ, Yung AR, et al. Progressive gray matter reduction of the superior temporal gyrus during transition to psychosis. Arch Gen Psychiatry. 2009;66(4):366-76. doi:10.1001/ archgenpsychiatry.2009.12.

41. Tognin S, Riecher-Rössler A, Meisenzahl EM, Wood SJ, Hutton C, Borgwardt SJ et al. Reduced parahippocampal cortical thickness in subjects at ultra-high risk for psychosis. Psychol Med. 2014;44(03): 489-498. doi:10.1017/S0033291713000998.

42. Cannon TD, Chung Y, He G, Sun D, Jacobson A, van Erp TGM et al. Progressive reduction in cortical thickness as psychosis develops: a multisite longitudinal neuroimaging study of youth at elevated clinical risk. Biol Psychiatr. 2015;77:147-57. doi:10. 1016/j.biopsych.2014.05.023.

43. Van Tricht MJ, Ruhrmann S, Arns M, Müller R, Bodatsch M, Velthorst $\mathrm{E}$ et al. Can quantitative EEG measures predict clinical outcome in subjects at clinical high risk for psychosis? A prospective multicenter study. Schizophr Res. 2014;153(1):42-47. doi:10. 1016/j.schres.2014.01.019.

44. Andreou C, Faber PL, Leicht G, Schoettle D, Polomac N, HanganuOpatz IL et al. Resting-state connectivity in the prodromal phase of schizophrenia: insights from EEG microstates. Schizophr Res. 2014;152(2-3):513-520. doi:10.1016/j.schres.2013.12.008.

45. Perez VB, Woods SW, Roach BJ, Ford JM, McGlashan TH, Srihari $\mathrm{VH}$, et al. Automatic auditory processing deficits in schizophrenia and clinical high-risk patients: forecasting psychosis risk with mismatch negativity. Biol Psychiatry. 2014;75(6):459-69. doi:10. 1016/j.biopsych.2013.07.038.

46. Walker EF, Trotman HD, Goulding SM, Holtzman CW, Ryan AT, McDonald A et al. Developmental mechanisms in the prodrome to psychosis. Dev Psychopathol. 2013;25(25th Anniversary Special Issue 4pt2):1585-1600. doi:10.1017/S0954579413000783.

47. Walker E, Mittal V, Tessner K. Stress and the hypothalamic pituitary adrenal axis in the developmental course of schizophrenia. Annu Rev Clin Psychol. 2008;4(1):189-216. doi:10.1146/ annurev.clinpsy.4.022007.141248.

48. Day FL, Valmaggia LR, Mondelli V, Papadopoulos A, Papadopoulos I, Pariante CM, et al. Blunted cortisol awakening response in people at ultra high risk of developing psychosis. Schizophr Res. 2014;158(1-3):25-31. doi:10.1016/j.schres.2014. 06.041 .

49. Walker EF, Trotman HD, Pearce BD, Addington J, Cadenhead KS, Cornblatt BA et al. Cortisol levels and risk for psychosis: initial findings from the North American Prodrome Longitudinal Study. Biol. Psychiatr. 2013;74(6):410-417. doi:10.1016/j.biopsych.2013. 02.016.

50. Bergink V, Gibney SM, Drexhage HA. Autoimmunity, inflammation, and psychosis: a search for peripheral markers. Biol Psychiatry. 2014;75(4):324-31. doi:10.1016/j.biopsych.2013.09. 037.

51. Hui C, Morcillo C, Russo DA, Stochl J, Shelley GF, Painter M et al. Psychiatric morbidity, functioning and quality of life in young people at clinical high risk for psychosis. Schizophr Res. 2013;148(13):175-180. doi:10.1016/j.schres.2013.05.026.

52. Manninen M, Lindgren M, Therman S, Huttunen M, Ebeling H, Moilanen I, et al. Clinical high-risk state does not predict later psychosis in a delinquent adolescent population. Early Interv Psychiatr. 2014;8(1):87-90. doi:10.1111/eip.12045.

53. Lindgren $\mathrm{M}$, Manninen $\mathrm{M}$, Kalska $\mathrm{H}$, Mustonen U, Laajasalo T, Moilanen $\mathrm{K}$ et al. Predicting psychosis in a general adolescent 
psychiatric sample. Schizophr Res. 2014;158(1-3):1-6. doi:10. 1016/j.schres.2014.06.028.

54. Fisher HL, Caspi A, Poulton R, Meier MH, Houts R, Harrington H et al. Specificity of childhood psychotic symptoms for predicting schizophrenia by 38 years of age: a birth cohort study. Psychol Med. 2013;43(10):2077-2086. doi:10.1017/S0033291712003091.

55. De Wit S, Schothorst PF, Oranje B, Ziermans TB, Durston S, Kahn RS. Adolescents at ultra-high risk for psychosis: long-term outcome of individuals who recover from their at-risk state. Eur Neuropsychopharmacol. 2014;24(6):865-73. doi:10.1016/j. euroneuro.2014.02.008

56. Fusar-Poli P, Van Os J. Lost in transition: setting the psychosis threshold in prodromal research. Acta Psychiatr Scand. 2013;127(3):248-52. doi:10.1111/acps.12028.

57. Fusar-Poli P, Yung AR, McGorry P, van Os J. Lessons learned from the psychosis high-risk state: towards a general staging model of prodromal intervention. Psychol Med. 2014;44(01):17-24. doi:10. 1017/S0033291713000184.

58. Simon AE, Borgwardt S, Riecher-Rössler A, Velthorst E, de Haan L, Fusar-Poli P. Moving beyond transition outcomes: meta-analysis of remission rates in individuals at high clinical risk for psychosis. Psychiatry Res. 2013;209(3):266-72. doi:10.1016/j.psychres.2013. 03.004 .

59. Schultze-Lutter F, Klosterkötter J, Ruhrmann S. Improving the clinical prediction of psychosis by combining ultra-high risk criteria and cognitive basic symptoms. Schizophr Res. 2014;154(1-3): 100-6. doi:10.1016/j.schres.2014.02.010.

60. Fusar-Poli P, Bechdolf A, Taylor MJ, Bonoldi I, Carpenter WT, Yung AR, et al. At risk for schizophrenic or affective psychoses? A meta-analysis of DSM/ICD diagnostic outcomes in individuals at high clinical risk. Schizophr Bull. 2013;39(4):923-32. doi:10.1093/ schbul $/ \mathrm{sbs} 060$

61. Gale C, Glue P, Gallagher S. Bayesian analysis of posttest predictive value of screening instruments for the psychosis high-risk state. JAMA Psychiatr. 2013;70(8):880-1. doi:10.1001/jamapsychiatry. 2013.1320.

62. Association AP. Diagnostic and Statistical Manual of Mental Disorders, 5th Edition: DSM-5 (5 edition.). Washington, D.C.: American Psychiatric Publishing; 2013.

63. Fusar-Poli P, Carpenter WT, Woods SW, McGlashan TH. Attenuated psychosis syndrome: ready for DSM-5.1? Annu Rev Clin Psychol. 2014;10(1):155-92. doi:10.1146/annurev-clinpsy032813-153645.

64. Tsuang MT, Van Os J, Tandon R, Barch DM, Bustillo J, Gaebel W et al. Attenuated psychosis syndrome in DSM-5. Schizophr Res. 2013;150(1):31-35. doi:10.1016/j.schres.2013.05.004.

65. Shah JL, Tandon N, Keshavan MS. Psychosis prediction and clinical utility in familial high-risk studies: selective review, synthesis, and implications for early detection and intervention. Early Interv Psychiatr. 2013;7(4):345-60. doi:10.1111/eip.12054. Literature review of predictors of psychosis among genetic high-risk cohorts suggests no existing markers for accurate prediction.

66. Singh F, DeJoseph M, Cadenhead KS. Therapeutic considerations in individuals at clinical risk for developing psychosis. Curr Treat Options Psychiatr. 2014;1(2):134-48. doi:10.1007/s40501-0140009-2.

67. Liu C-C, Demjaha A. Antipsychotic interventions in prodromal psychosis. CNS Drugs. 2013;27(3):197-205. doi:10.1007/ s40263-013-0046-1.

68. Mossaheb N, Schäfer MR, Schlögelhofer M, Klier CM, Cotton SM, McGorry PD, et al. Effect of omega-3 fatty acids for indicated prevention of young patients at risk for psychosis: when do they begin to be effective? Schizophr Res. 2013;148(1-3):163-7. doi: 10.1016/j.schres.2013.05.027

69. Woods SW, Walsh BC, Hawkins KA, Miller TJ, Saksa JR, D'Souza $\mathrm{DC}$ et al. Glycine treatment of the risk syndrome for psychosis: report of two pilot studies. Eur Neuropsychopharmacol. 2013;23(8):931-940. doi:10.1016/j.euroneuro.2012.09.008.

70. Van der Gaag M, Smit F, Bechdolf A, French P, Linszen DH, Yung AR et al. Preventing a first episode of psychosis: meta-analysis of randomized controlled prevention trials of 12 month and longerterm follow-ups. Schizophr Res. 2013;149(1-3):56-62. doi:10. 1016/j.schres.2013.07.004.

71. Hutton P, Taylor PJ. Cognitive behavioural therapy for psychosis prevention: a systematic review and meta-analysis. Psychol Med. 2014;44(03):449-68. doi:10.1017/S0033291713000354.

72. Okuzawa N, Kline E, Fuertes J, Negi S, Reeves G, Himelhoch S, Schiffman J. Psychotherapy for adolescents and young adults at high risk for psychosis: a systematic review. Early Interv Psychiatr. 2014;n/a-n/a. doi:10.1111/eip.12129.

73. Byrne RE, Morrison AP. Young people at risk of psychosis: their subjective experiences of monitoring and cognitive behaviour therapy in the early detection and intervention evaluation 2 trial. Psychol Psychother Theory Res Pract. 2014;87(3):357-71. doi: 10.1111/papt.12013.

74. Miklowitz DJ, O’Brien MP, Schlosser DA, Addington J, Candan KA, Marshall C et al. Family-focused treatment for adolescents and young adults at high risk for psychosis: results of a randomized trial. J Am Acad Child Adolesc Psychiatr. 2014;53(8):848-858. doi:10. 1016/j.jaac.2014.04.020.

75. Fisher M, Loewy R, Hardy K, Schlosser D, Vinogradov S. Cognitive interventions targeting brain plasticity in the prodromal and early phases of schizophrenia. Annu Rev Clin Psychol. 2013;9(1):435-63. doi:10.1146/annurev-clinpsy-032511-143134.

76. Stafford MR, Jackson H, Mayo-Wilson E, Morrison AP, Kendall T. Early interventions to prevent psychosis: systematic review and meta-analysis. BMJ. 2013;346(jan18 1), f185-f185. doi:10.1136/ bmj.f185. Reviews randomized trials of psychological, pharmacological, and nutritional treatments as possible psychosis prevention methods and suggests some evidence for cognitive behavioral therapy and omega-3 fatty acids.

77. McGorry PD, Nelson B, Phillips LJ, Yuen HP, Francey SM, Thampi A et al. Randomized controlled trial of interventions for young people at ultra-high risk of psychosis: twelve-month outcome. J Clin Psychiatr. 2013;74(04):349-356. doi:10.4088/JCP. $12 \mathrm{~m} 07785$.

78. Fridgen GJ, Aston J, Gschwandtner U, Pflueger M, Zimmermann R, Studerus E et al. Help-seeking and pathways to care in the early stages of psychosis. Social Psychiatr Psychiatr Epidemiol. 2013;48(7):1033-1043. doi:10.1007/s00127-012-0628-0.

79. Von Reventlow HG, Krüger-Özgürdal S, Ruhrmann S, SchultzeLutter F, Heinz A, Patterson P et al. Pathways to care in subjects at high risk for psychotic disorders-a European perspective. Schizophr Res. 2014;152(2-3):400-407. doi:10.1016/j.schres. 2013.11.031.

80. Alderman T, Addington J, Bearden C, Cannon TD, Cornblatt BA, McGlashan $\mathrm{TH}$ et al. Negative symptoms and impaired social functioning predict later psychosis in Latino youth at clinical high risk in the North American prodromal longitudinal studies consortium. Early Interv Psychiatr. 2014; doi:10. 1111/eip.12128.

81. Hughes F, Stavely H, Simpson R, Goldstone S, Pennell K, McGorry P. At the heart of an early psychosis centre: the core components of the 2014 Early Psychosis Prevention and Intervention Centre model for Australian communities. Aust Psychiatr. 2014;22(3):228-34. doi:10.1177/1039856214530479.

82. Mueser KT, Deavers F, Penn DL, Cassisi JE. Psychosocial treatments for schizophrenia. Annu Rev Clin Psychol. 2013;9(1):46597. doi:10.1146/annurev-clinpsy-050212-185620.

83. Morrison AP, Turkington D, Pyle M, Spencer H, Brabban A, Dunn $\mathrm{G}$ et al. Cognitive therapy for people with schizophrenia spectrum disorders not taking antipsychotic drugs: a single-blind randomised 
controlled trial. Lancet. 2014;383(9926):1395-1403. doi:10.1016/ S0140-6736(13)62246-1.

84. Khoury B, Lecomte T, Gaudiano BA, Paquin K. Mindfulness interventions for psychosis: a meta-analysis. Schizophr Res. 2013;150(1):176-84. doi:10.1016/j.schres.2013.07.055.

85. Morrison AP, Pyle M, Chapman N, French P, Parker SK, Wells A. Metacognitive therapy in people with a schizophrenia spectrum diagnosis and medication resistant symptoms: a feasibility study. $\mathrm{J}$ Behav Ther Exp Psychiatry. 2014;45(2):280-4. doi:10.1016/j. jbtep.2013.11.003.

86. Hedman AM, van Haren NEM, van Baal CGM, Kahn RS, Hulshoff Pol HE. IQ change over time in schizophrenia and healthy individuals: a meta-analysis. Schizophr Res. 2013;146(1-3):201-8. doi: 10.1016/j.schres.2013.01.027.

87. Bowie CR, Grossman M, Gupta M, Oyewumi LK, Harvey PD. Cognitive remediation in schizophrenia: efficacy and effectiveness in patients with early versus long-term course of illness. Early Interv Psychiatr. 2014;8(1):32-8. doi:10.1111/eip.12029.

88. Puig O, Penadés R, Baeza I, De la Serna E, Sánchez-Gistau V, Bernardo $\mathrm{M}$, et al. Cognitive remediation therapy in adolescents with early-onset schizophrenia: a randomized controlled trial. J Am Acad Child Adolesc Psychiatr. 2014;53(8):859-68. doi:10. 1016/j.jaac.2014.05.012.

89. Drake RJ, Day CJ, Picucci R, Warburton J, Larkin W, Husain N et al. A naturalistic, randomized, controlled trial combining cognitive remediation with cognitive-behavioural therapy after firstepisode non-affective psychosis. Psychol Med. 2014;44(09): 1889-1899. doi:10.1017/S0033291713002559.

90. Tully LM, Niendam TA. Beyond "cold" cognition: exploring cognitive control of emotion as a risk factor for psychosis. Curr Behav Neurosci Rep. 2014;1(3):170-81. doi:10.1007/ s40473-014-0016-z.

91. Kline E, Schiffman J. Psychosis risk screening: a systematic review. Schizophr Res. 2014;158(1-3):11-8. doi:10.1016/j.schres.2014.06. 036.

92. Zhang T, Li H, Woodberry KA, Seidman LJ, Zheng L, Li H et al. Prodromal psychosis detection in a counseling center population in China: an epidemiological and clinical study. Schizophr Res. 2014;152(2-3):391-399. doi:10.1016/j.schres. 2013.11.039. 